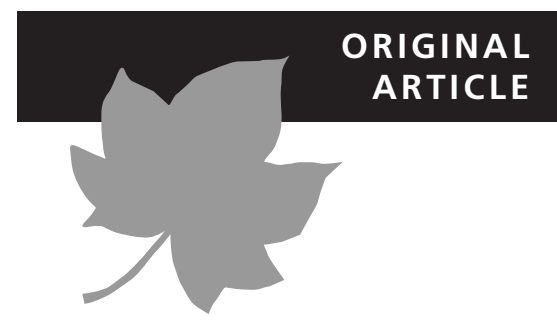

\title{
Dynamics of core and occasional species in the marine plankton: tintinnid ciliates in the north-west Mediterranean Sea
}

John R. Dolan ${ }^{1 \star}$, Mark E. Ritchie ${ }^{2}$, Alina Tunin-Ley ${ }^{1}$ and Marie-Dominique Pizay $^{1}$

${ }^{1}$ Microbial Ecology Group, Université Paris 6 UMR CNRS/INSU 7093, Laboratoire d'Océanographie de Villefranche, Villefranchesur-Mer, France and ${ }^{2}$ Biology Department, Syracuse University, Syracuse, NY, USA
${ }^{*}$ Correspondence: John R. Dolan, Microbial Ecology Group, Laboratoire d'Océanographie de Villefranche, Villefranche-sur-Mer, France. E-mail: dolan@obs-vlfr.fr

\section{ABSTRACT}

Aim To assess short-term variability in the community composition and community structure of tintinnid ciliates, herbivores of the microzooplankton.

Location North-west Mediterranean Sea.

Methods We sampled on 18 dates over a 4-week period in 2004 at an openwater site. Species were classified as 'core species', found on every date, or 'occasional species', absent on one or more dates. Species abundance distributions of the entire community, and separately the core and occasional species, were compared with geometric, log-series and log-normal distributions. Core and occasional species were compared in terms of the shell or lorica oral diameter (LOD), analogous to gape size.

Results We found 11 core and 49 occasional species. Diversity metrics were stable compared with shifts in abundances. Core species accounted for the majority of individuals in all samples. On each date, 9-22 occasional species, representing $10-15 \%$ of the population, were found. Species richness of the occasionals was positively related to population size. The identities of the occasional species found were unrelated to the time between sampling. The species abundance distribution of the occasional population was best fit by a log-series distribution, while that of the core species was best fit by a log-normal distribution. The species abundance distribution of the entire community was best fit by a log-series distribution. Most of the occasional species had LODs distinct from that of a core species and occupied size classes left empty by the core population. However, the most abundant and frequent of the occasional species had a LOD similar to that of a core species.

Main conclusions Among tintinnids, which are planktonic protists, occasional species have a species abundance distribution pattern distinct from that of core species. Occasional species appeared to be composed of two groups, one of relatively abundant species and similar to core species, and a second group of ephemeral species with morphologies distinct from core species. The existence of two categories of occasional or rare species may be common: (1) those similar to, and thus perhaps able to replace, dominant species in the absence of a change in the environment; and (2) those distinct from dominant species and requiring different conditions to prosper.

\section{Keywords}

Core species, marine plankton, microbial biogeography, morphological diversity, rare species, satellite species, species abundance distribution, species-time. 


\section{INTRODUCTION}

Microbes appear to follow many basic large-scale biogeographical patterns known from studies of multicellular organisms (e.g. Dolan, 2005, 2006; Soininen \& Heine, 2005). However, most microbes are capable of rapid generation times $(<24 \mathrm{~h})$ and wide dispersal; consequently, the community composition of microbial populations can potentially change quite rapidly. Here we use the term 'community' to designate an assemblage of ecologically similar, coexisting organisms. Planktonic microbes are especially interesting groups in which to examine the dynamics of community composition as there are many species-rich groups with apparently similar ecological niches, 'the paradox of the plankton' (Hutchinson, 1961). Solutions to this paradox have been proposed, interestingly, in the near absence of data on the stability of community composition and structure over time-scales of relevance with regard to microbes.

Here we present the results of a study of tintinnid ciliates, a species-rich group of planktonic ciliates. Tintinnids form an order of the ciliate subclass Choreotrichia. They are all planktonic, part of the microzooplankton, grazers on phytoplankton prey of $2-50 \mu \mathrm{m}$ in size. Tintinnids are characterized by the possession of a species-specific tube or vase-shaped shell, termed a lorica. Like their prey, tintinnids reproduce by binary fission and are capable of rapid growth, e.g. generation times of $16 \mathrm{~h}$ in natural populations (e.g. Dolan \& Gallegos, 2001). They are modestly motile with extrapolation of swimming rates measured in laboratory studies suggesting a range of tens of metres per day (e.g. Broglio et al., 2001).

We monitored a tintinnid community in the surface layer (0-90 m depth) at near daily intervals over a 4-week period. Our objectives were: (1) to assess the stability of community composition over short time periods (days) in planktonic microorganisms capable of rapid growth; and (2) to provide evidence of community structure by examining patterns of relative species abundance.

\section{MATERIALS AND METHODS}

\section{Model organisms}

Tintinnids are found in the surface waters of nearly all marine and estuarine systems. They are a very species-rich group; the standard taxonomic monographs of Kofoid \& Campbell (1929, 1939) catalogue over 700 species. Large-scale biogeographical patterns are well known. Most genera can be characterized as predominately found in either coastal or open waters and as temperate, tropical, or high-latitude fauna (e.g. Pierce \& Turner, 1993). Tintinnids supply a textbook example of the latitudinal species gradient (e.g. Gaston \& Spicer, 2003, p. 73). In the Mediterranean Sea, $c .100$ species have been catalogued (Jörgensen, 1924; Dolan, 2000). A single location in the northwest Mediterranean can harbour up to 39 species on a single date (Cariou et al., 1999).
Tintinnids range in size from 30 to $300 \mu \mathrm{m}$. Identifications are based on characteristics of the lorica (or shell) into which the ciliate cell can withdraw. The general shape of the lorica of a tintinnid is a tube or vase, but with quite distinct morphologies (e.g. Fig. 1). Like foraminifera and radiolarians, characteristics of gross morphology define species despite the fact that some genera are known to display plasticity in lorica morphology (e.g. Williams et al., 1994).

In terms of a functional group, tintinnid ciliates are part of the microzooplankton, herbivores feeding primarily on small (2-20 $\mu \mathrm{m})$ phytoplankton. Occasionally the feeding activity of tintinnids can dominate the consumption of phytoplankton (e.g. Karayanni et al., 2005) but they are generally a minority component of the microzooplankton compared with other protists such as oligotrich ciliates or heterotrophic dinoflagellates. Swimming speeds of tintinnids are in the range of a few metres per hour (e.g. Broglio et al., 2001).

Gape size in the form of the diameter of the mouth end of the lorica, the lorica oral diameter (LOD), is related to the size of the food items ingested. The largest prey ingested is about half the LOD in longest dimension (Heinbokel, 1978) and they feed most efficiently, removing prey at maximum rates, on prey that is c. 25\% of the LOD in size (Dolan et al., 2002).

Tintinnids, in contrast to other groups of planktonic ciliates, for example 'oligotrichs', are a single order even among competing ciliate classification schemes. According to traditional ciliate taxonomy, and in agreement with the molecular data available to date (Agatha \& Strüder-Kypke, 2007), they are a monophyletic group. Thus tintinnids are a coherent group ecologically as microzooplankters, morphologically as loricate ciliates and phylogenetically as members of the order Tintinnida.

\section{Tintinnid sampling and sample analysis}

Sampling was conducted through the oceanographic project Dynaproc II. The programme was centred around observing short-term variability in water column processes at a site with weak vertical advection [see special issue of Biogeosciences (http://www.biogeosciences-discuss.net/special_issue35.html)]. The sampling station location, $43^{\circ} 25^{\prime} \mathrm{N}, 8^{\circ} \mathrm{E}$, is about midway between the island of Corsica and the French coast in the north-west Mediterranean Sea. On 18 dates between 14 September and 14 October 2004, six depths were sampled between the surface and $90 \mathrm{~m}$ using a 20-L Niskin bottle. For each discrete-depth sample, a 10-L volume was concentrated to $20 \mathrm{~mL}$ by slowly and gently pouring the water through a 20 $\mu \mathrm{m}$ mesh Nitex screen fixed to the bottom of a $10-\mathrm{cm}$ diameter PVC tube. Concentrated water samples were fixed with Lugol's solution ( $2 \%$ final concentration), were settled in sedimentation chambers and examined using an inverted microscope at $200 \times$ total magnification. Thus, for each date, material from $60 \mathrm{~L}$ of water was examined, yielding a total of over 17,000 individuals for the 18 dates.

Tintinnid identifications were made based on lorica morphology and following Kofoid \& Campbell (1929, 1939) and Marshall (1969). Species of certain genera are known to display 
Figure 1 'Core' species of tintinnids: (a) Salpingella attenuata, (b) Salpingella decurtata, (c) Salpingella faurei, (d) Eutintinnus tubulosa, (e) Dictyocysta mitra, (f) Dadayiella ganymedes, (g) Epliocyclis undella, (h) Protohabdonella curta, (i) Cantheriella pyrimidata, (j) Acanthostomella conicoides, (k) Amphorella quadrilineata. Core species were found on every sampling date and were the most abundant species overall.

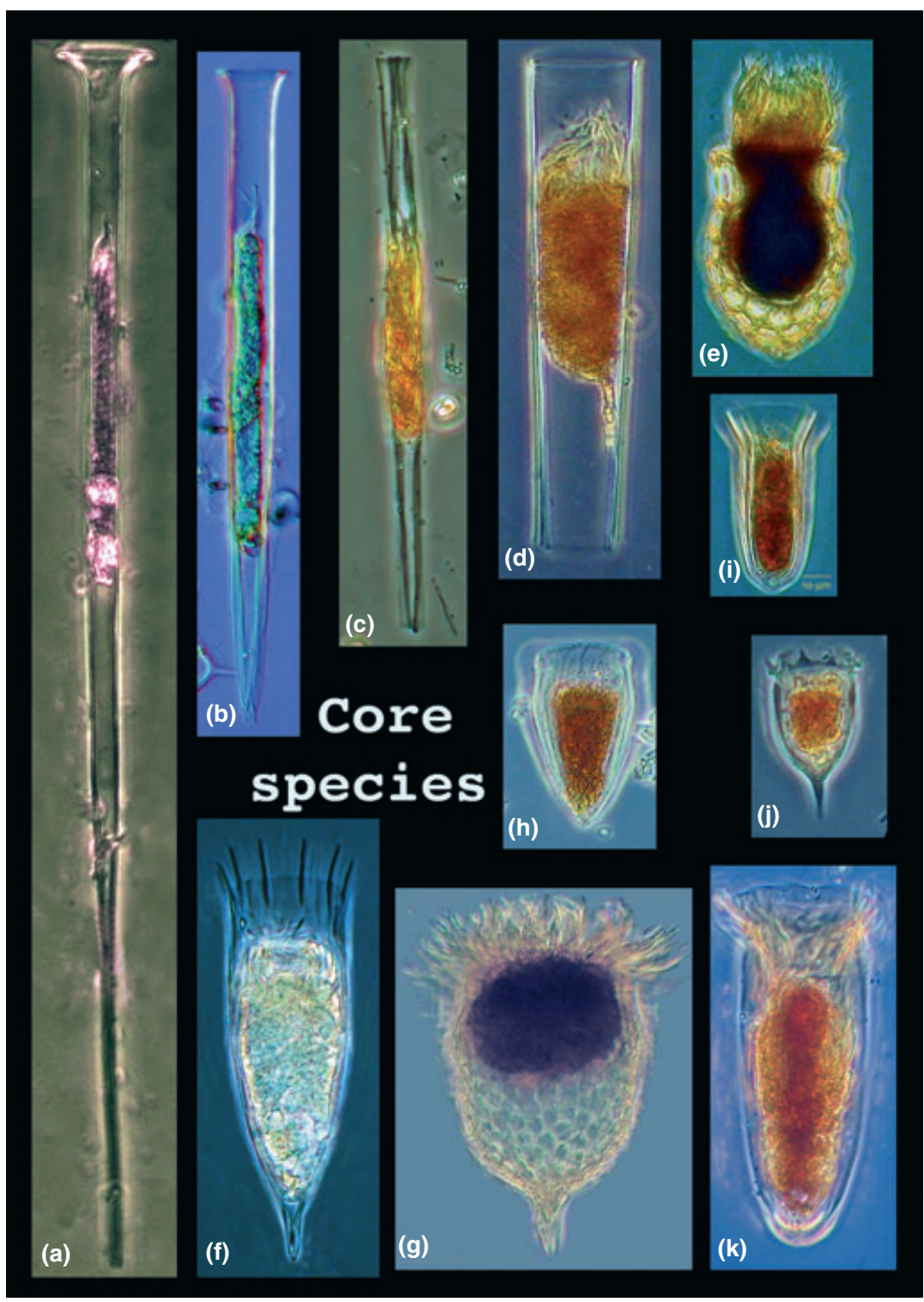

different lorica morphologies (e.g. Gold \& Morales, 1976; Davis, 1981; Laval-Peuto, 1983; Wasik, 1988; Williams et al., 1994). However, only a few of the species encountered in this study appeared variable and may or may not represent single species (Tintinnopsis rapa-parva, Favella spp., Climacocylis spp.). We adopted a conservative approach, pooling apparent varieties. Empty lorica were not enumerated. For each station, data from all samples were pooled. Average cell concentrations were calculated from total counts divided by total original water sample volumes.

Taxonomic diversity was estimated for each sample as the Shannon index (ln-based, e.g. Magurran, 2004) and species richness. Morphological categories consisted of LOD size classes (Dolan et al., 2006). Each species was assigned the average dimensions reported in Kofoid \& Campbell (1929, 1939), Campbell (1942) and Marshall (1969). Size-class diameters were binned over $4-\mu \mathrm{m}$ intervals beginning with the overall smallest diameter $(12 \mu \mathrm{m})$ and continuing to the largest diameter encountered in a given sample.
We constructed log-rank abundance curves for the tintinnid assemblages of each sampling date by calculating the relative abundance for each species and ranking species from highest to lowest and plotting $\ln$ (relative abundance) vs. rank. We distinguished two sets of species: core species, defined as those present on each of the 18 sampling dates; and occasional species, defined as those not detected on one or more dates. Then, for each entire assemblage as well as separately for the core and occasional species, we constructed hypothetical logrank abundance curves that could fit the data by using parameters of the particular assemblage. We constructed curves for three different models of community organization: geometric series, log-series, and log-normal, as in Dolan et al. (2007).

A geometric series distribution represents the result of the priority exploitation of resources by species arriving sequentially in a community (Whittaker, 1972), and is modelled by assuming that each species' abundance is proportional to a fixed proportion $p$ of remaining resources. Thus the relative 


\section{J. R. Dolan et al.}

abundance of the $i$ th species is $(1-p) p^{i-1}$. For the tintinnid samples we used the relative abundance of the most abundant species to estimate $p$.

A log-series distribution represents the result of random dispersal from a larger community, a metacommunity in Hubbell's neutral theory (Hubbell, 2001). In a community exhibiting a log-series distribution, species having abundance $n$ occur with frequency $\alpha x^{n} / n$, where $x$ is a fitted parameter and $\alpha$ is Fisher's alpha, a measure of species diversity that is independent of total community abundance. For a given community with $N$ total individuals and $S$ species, $x$ can be found (Magurran, 2004) by iteratively solving the following equation for $x: S / N=-\ln (1-x)(1-x) / x$ and then finding Fisher's alpha as $\alpha=N(1-x) / x$. For the tintinnid assemblages, we simply used the observed $S$ and $N$ for each sample to calculate $x$ and $\alpha$.

A log-normal species abundance distribution is thought to result from either a large number of species of independent population dynamics with randomly varying (in either space or time) exponential growth, such that $N(i) \propto \mathrm{e}^{r i}$, where $r_{i}$ is a random variable. As $N(i)$ is a function of an exponential variable, $\ln (N(i))$ should be normally distributed (May, 1975). Alternatively, species in a community that are limited by multiple factors that act on population size in a multiplicative fashion should also exhibit a log-normal distribution of abundances. We calculated the expected log-normal species abundance distribution for each tintinnid sample by calculating the mean and standard deviation of $\ln$ (abundance) and using these parameters to generate expected abundance distributions for the $S$ species in the sample using the NORMsinv function in an Excel ${ }^{\circledR}$ spreadsheet. We calculated the mean abundance for each species, ranked from highest to lowest, and then calculated relative abundance.
For each date, the observed rank abundance distributions for the three sets of species (entire community, core species, occasional species), were compared with the hypothetical models using a Bayesian approach: an Akaike goodness of fit test (Burnham \& Anderson, 2002). In this test, an Akaike information criterion (AIC) was determined as the natural logarithm of the mean (sum divided by $S$ ) of squared deviations between observed and predicted $\ln$ (relative abundance) for all ranked species $S$ plus an additional term to correct for the number of estimated parameters, $k$ ( 1 for geometric series and 2 each for log-series and log-normal distributions): $(S+k) /(S-\mathrm{k}-2)$. The lower the calculated AIC value, the better the fit. A difference of 1 in AIC roughly corresponds to a three-fold difference in fit, so this test statistic is sensitive enough for our data to judge the fit of the three different models.

\section{RESULTS}

\section{General trends}

Most individuals were found at intermediate depths and there were no detectable differences in species assemblages with depth. Temporally, concentrations of organisms varied over nearly an order of magnitude. In contrast, both numbers of species or values of the Shannon index $\left(H^{\prime}\right)$ varied by little more than $\pm 25 \%$ of the average values of 28 species and an $H^{\prime}$ value of 2.5 (Fig. 2), respectively. On each sampling date, between 21 and 34 species were found, but only 11 species were found consistently. For a given species, overall abundance was related to frequency of presence, with the 11 consistently found species showing the highest abundances, separating them from 49 other species as 'core species' (Fig. 3). The core species accounted for the majority of all individuals at all depths but,

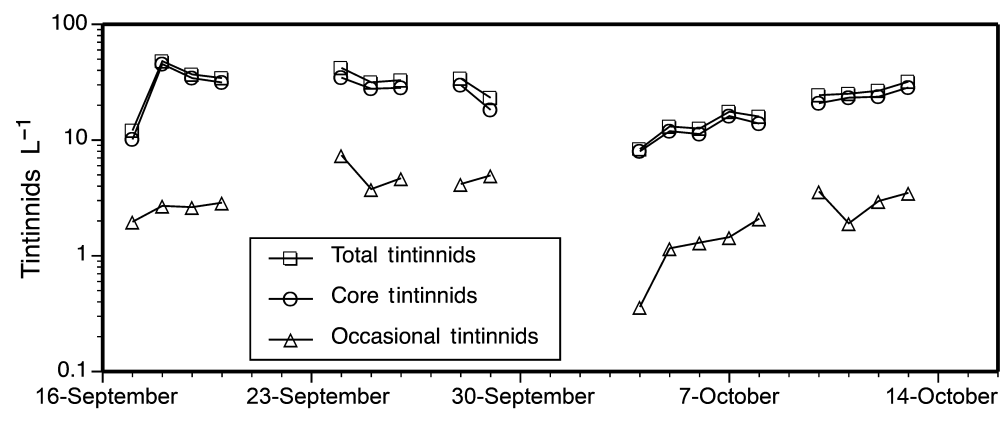

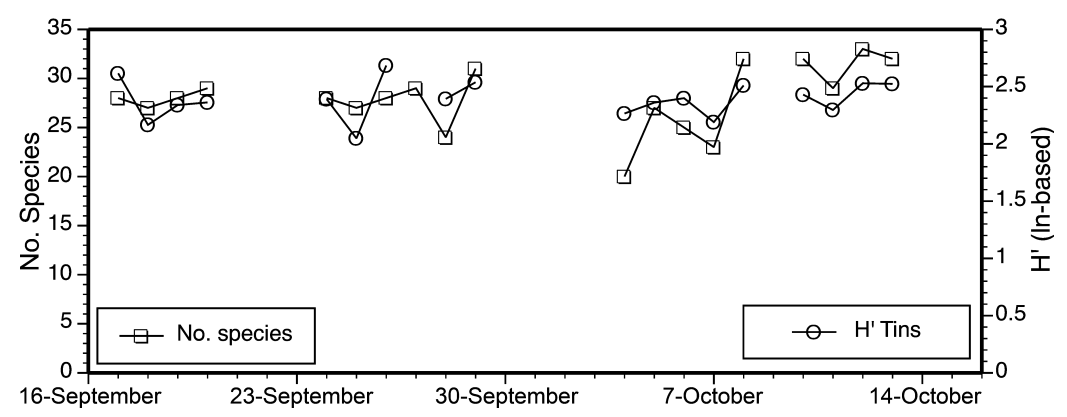

Figure 2 Temporal changes in the abundance of tintinnid ciliates (top panel) and diversity parameters of the tintinnid community (bottom panel) in the north-west Mediterranean Sea in 2004. Note that compared with changes in abundance, diversity remained relatively stable. 


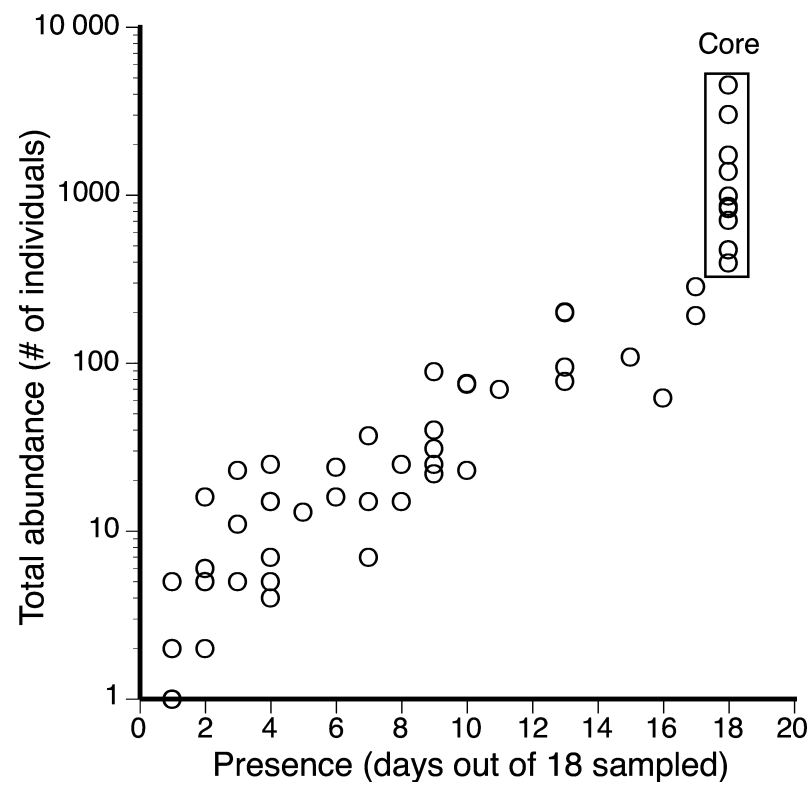

Figure 3 Scatterplot of the total overall abundance and days present for each of the tintinnid species found. The group of 11 species consistently present and most abundant defined the core species set. All other species were classified as 'occasional species'.

on each date, 9-22 species other than core species, termed here 'occasional species', were encountered. The species richness of the occasional tintinnids was positively related to their concentration, which was itself positively related to the concentration of core species (Fig. 4). Thus, a dense population of tintinnids contained more occasional species than a sparse population, as expected from rarefaction (Gotelli \& Colwell, 2001). The pool of occasional species found varied considerably from day to day. Indeed, the day-to-day variation in occasional species was sufficiently large that time between samples was unrelated to similarity in the set of occasional species found (Fig. 5).

\section{Morphological characteristics of core and occasional species}

The 11 core species were distributed among seven size classes of LOD between 14 and $52 \mu \mathrm{m}$ (Fig. 6). A single size class

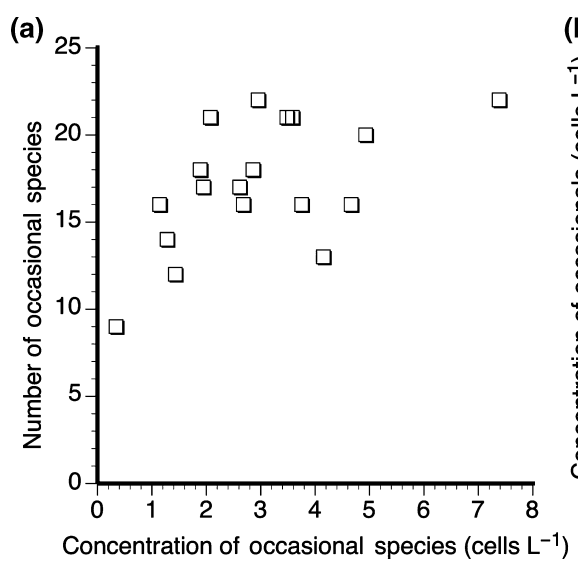

Figure 4 The relationships between (a) the number of occasional species and the size of the occasional population, and (b) the size of the occasional population and the size of the core population. As the abundance of the core species increases, the number of occasional species increases.

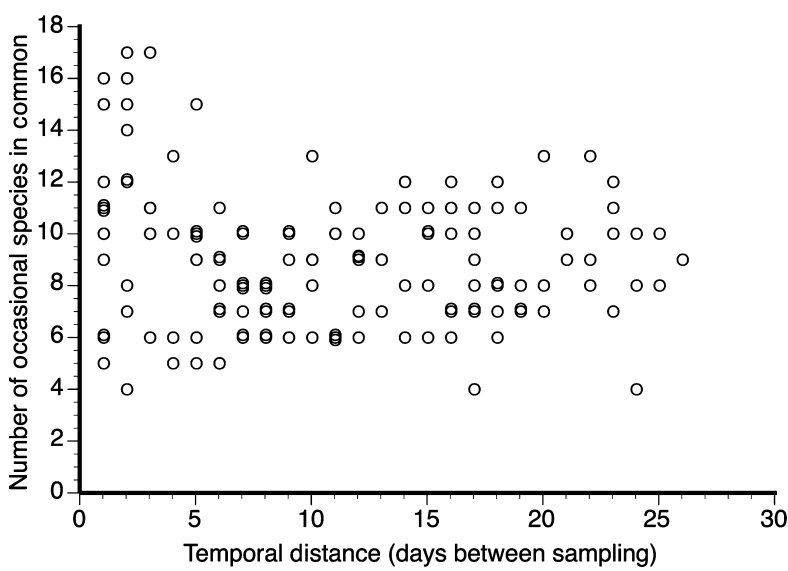

Figure 5 Scatterplot of the relationship between taxonomic similarity of the occasional population and temporal distance between sampling. Each sampling date was compared with all others and the number of occasional species in common was plotted as a function of days separating the sample dates. Temporal distance between samples was a poor predictor of the number of occasional species found in common.

(LOD diameter 16-20 $\mu \mathrm{m}$ ) contained slightly less than half of all individuals and comprised two species. The six other size classes each accounted for c. $10 \%$ of core species individuals. Core species did not show any obvious similarities in overall size and shape (Fig. 1).

The occasional species were composed of a wide range of LODs (LOD diameter 6-134 $\mu \mathrm{m}$ ). Most occasional species (45 of 49) fell within the range occupied by the core species. While only 16 occasional species shared a size class with one or more core species, these species accounted for $51 \%$ of the occasional population. Thus, 29 occasional species occupied size classes not containing a core species, but within the total size range of the core species, and these species represented about half the occasional population. Similar to the core species, the most abundant occasional species included a variety of overall shapes and sizes.

\section{Species abundance distributions}

The distributions of the entire tintinnid community most closely resembled log-series distributions; however, the core

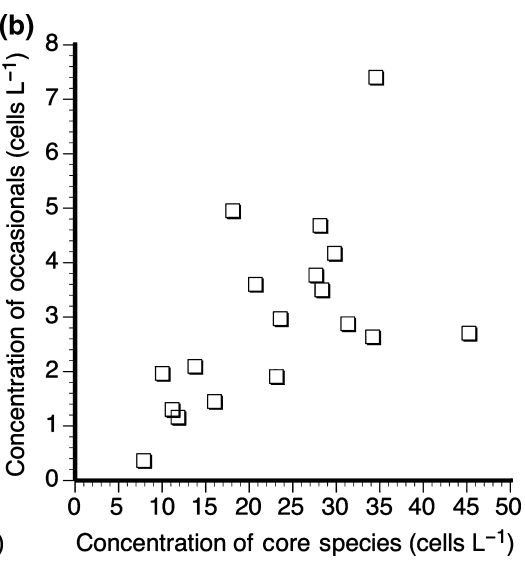




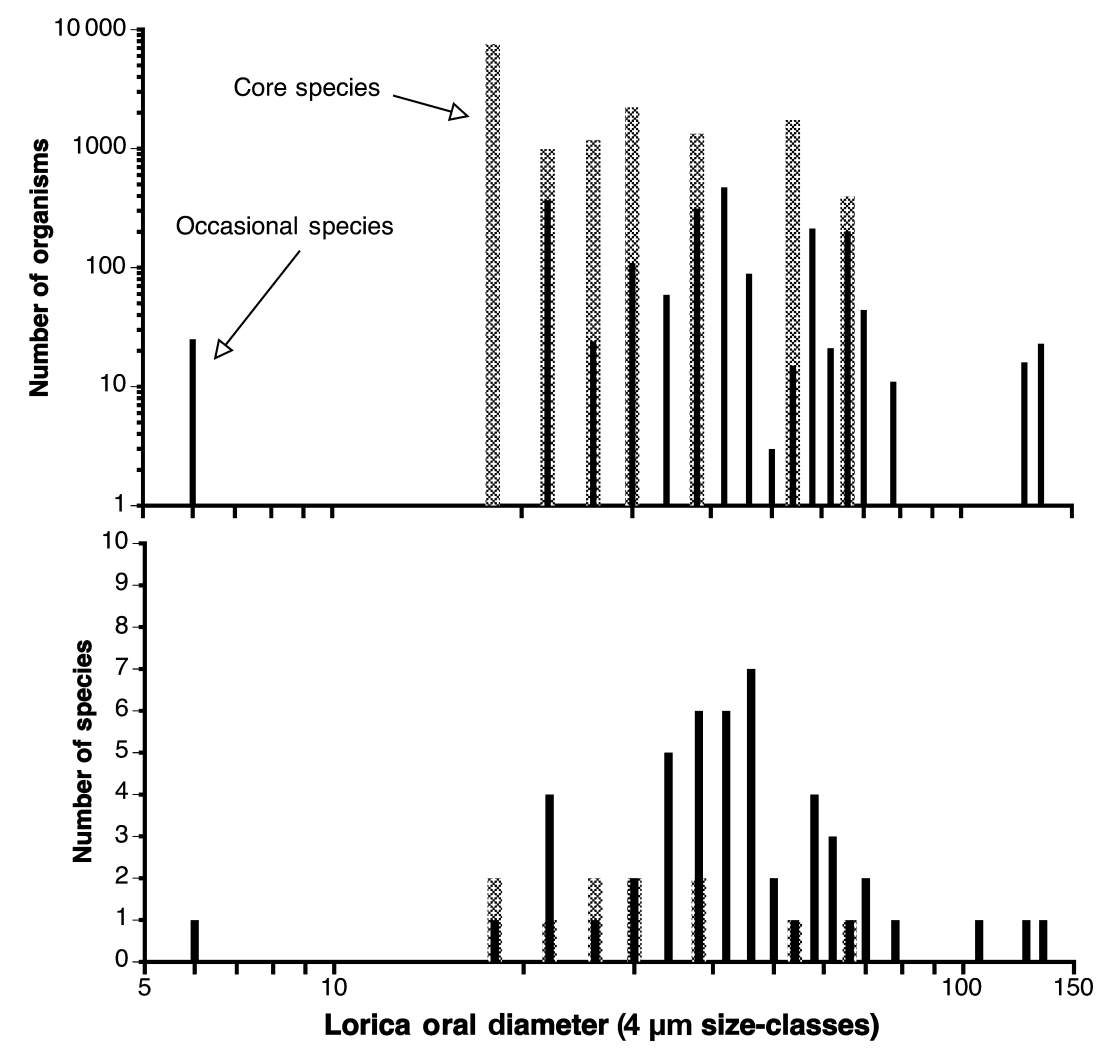

Figure 6 A comparison of core and occasional species in terms of gape sizes (lorica oral diameter). The top panel shows the numbers of organisms in different size classes, distinguishing core species and occasional species. Individuals of the core species assemblage (thick hatched lines) were more or less equitably distributed into seven size classes. Individuals of occasional species (thin solid lines) were found in a large number of size classes. However, the most populous size-classes were those corresponding to core species size classes. The bottom panel shows the numbers of core and occasional species found in different size classes. A size class contained only one or two core species (hatched line). Thus, core species appeared evenly distributed across the range of occupied size classes. In contrast, occasional species (thin solid lines) appeared to be distributed in a near-normal fashion around the mean size class of the core species. species and occasional species displayed different distributions (Table 1). Of the 18 dates sampled, core species abundances were most closely fitted by a log-normal distribution on 14 occasions and by a geometric distribution on four dates. In contrast, the distribution of occasional species was most often (on 13 of 18 dates) best fitted by a log-series distribution. The temporal changes in the fit of the best modelled distributions compared with actual species distributions for core, occasional and total species distributions appeared to be independent of one another (Table 1).

\section{DISCUSSION}

We found that a consistent set of patterns characterized planktonic protists in the open north-west Mediterranean Sea over the 4-week sampling period. Diversity metrics were relatively stable compared with shifts in population abundance. The tintinnid community as a whole generally showed a log-series distribution of species abundance, suggestive of a neutral community structure (Hubbell, 2001) and/or an intensively sampled population (McGill, 2003). Species catalogues varied from day to day but a set of 11 species were regularly found and accounted for most of the total concentrations. By distinguishing the 11 dominant species, we separated the tintinnid community into two groups - core and occasional forms - based simply on presence. Defining core vs. occasional is necessarily somewhat arbitrary. We employed the most simple and intuitively appealing criterion of 'always present' over the 4-week period sampled to distinguish core from occasional species.
The core species accounted for the majority of individuals at all depths and on all dates. Considering core species as a separate community, they often showed a log-normal distribution, as has been found with the 'core community' of other organisms with high dispersal capabilities, such as estuarine fish (Magurran \& Henderson, 2003), forest hymenopteran insects (Ulrich \& Ollik, 2004) or beetles (Ulrich \& Zalewski, 2006). In contrast, the occasional species of tintinnids were most often characterized by a log-series species abundance distribution, again recalling the transient portion of a fish population (Magurran \& Henderson, 2003) or insects (Ulrich \& Ollik, 2004; Ulrich \& Zalewski, 2006).

Sampling on multiple dates demonstrated consistency of the patterns. Furthermore, the deviations from the dominant distributions (core as log-normal, occasional as log-series) were independent temporally (Table 1 ). The distinct patterns of core and occasional species abundances suggests that the two groups of species may have distinct characteristics and dynamics. We found that consideration of the morphological characteristics of the two sets of species, in terms of gape size (LOD), suggests very different occupancy patterns.

Distributing the 11 core species into size classes of gape size results in the occupation of seven size classes with only two size classes containing more than one species (Fig. 6). Considering numbers of individuals, rather than species, in the core population, the distribution of numbers of organisms among the seven size classes was relatively equitable. In contrast, the 49 occasional species occupied 19 size classes. Rather than a nearly constant number of species per size class, the occasional species appeared to be normally distributed about the mean 
Table 1 Results of the analysis of tintinnid species abundance distributions considering only the core community (the 11 species always present), the 9-22 occasional species, and the entire tintinnid community.

\begin{tabular}{|c|c|c|c|c|c|c|c|c|c|c|c|}
\hline \multirow[b]{2}{*}{ Date } & \multicolumn{4}{|l|}{ Core } & \multicolumn{4}{|c|}{ Occasional } & \multicolumn{3}{|l|}{ Entire } \\
\hline & Normal & Geom & Series & No. spp. & Normal & Geom & Series & No. spp. & Normal & Geom & Series \\
\hline 17 September & -1.24 & -1.75 & 2.13 & 17 & 0.14 & 3.15 & -0.84 & 28 & 0.03 & -1.20 & -1.96 \\
\hline 18 September & -0.87 & 0.10 & 1.78 & 16 & 0.05 & 4.25 & 0.28 & 27 & 3.94 & 1.22 & 0.20 \\
\hline 19 September & -0.60 & -0.46 & 2.98 & 17 & -1.07 & 0.01 & -1.39 & 28 & 3.88 & 1.71 & -0.38 \\
\hline 20 September & -0.77 & -1.15 & 2.82 & 18 & -0.53 & 1.90 & -1.13 & 29 & 3.80 & 1.30 & -0.70 \\
\hline 24 September & 0.08 & 2.61 & 2.84 & 22 & -0.59 & -0.51 & -1.28 & 33 & -0.43 & 4.54 & -0.99 \\
\hline 25 September & -0.20 & 2.80 & 2.42 & 16 & -0.60 & -0.69 & -2.64 & 27 & -0.50 & 4.59 & -0.80 \\
\hline 26 September & -0.38 & 1.77 & 3.18 & 16 & 0.32 & 1.89 & -0.36 & 27 & -0.11 & 2.86 & -0.83 \\
\hline 28 September & -0.91 & 0.50 & 3.08 & 13 & -0.35 & 2.68 & 0.00 & 24 & -1.11 & 1.56 & -1.35 \\
\hline 29 September & 0.48 & 0.95 & 1.93 & 20 & 0.61 & 2.53 & -0.30 & 31 & -0.25 & 2.01 & -0.55 \\
\hline 4 October & -0.15 & 0.56 & 1.32 & 9 & -0.39 & 0.09 & -0.26 & 20 & 0.11 & -0.38 & -0.45 \\
\hline 5 October & -1.04 & -0.90 & 1.93 & 16 & -0.12 & 0.76 & -0.93 & 27 & 0.02 & 0.30 & 0.42 \\
\hline 6 October & -0.59 & -0.48 & 2.00 & 14 & -0.60 & -1.07 & -0.67 & 25 & -0.75 & 1.28 & -1.12 \\
\hline 7 October & -0.50 & 2.14 & 1.55 & 12 & 0.79 & 4.84 & 0.44 & 23 & -1.43 & 2.76 & -0.43 \\
\hline 8 October & -0.61 & 0.29 & 0.62 & 21 & -0.27 & 2.12 & -0.30 & 32 & -0.38 & 2.11 & -1.24 \\
\hline 10 October & -0.50 & -1.05 & 2.08 & 21 & -0.62 & -0.10 & -1.23 & 32 & -0.42 & 1.69 & -0.92 \\
\hline 11 October & -0.85 & -1.34 & 2.03 & 18 & -0.52 & -0.61 & -2.00 & 29 & -0.02 & 1.34 & 0.24 \\
\hline 12 October & -0.89 & -0.24 & 2.42 & 22 & -1.45 & -1.64 & -0.56 & 33 & -0.28 & -0.18 & -0.85 \\
\hline 13 October & -1.55 & -1.04 & 3.13 & 21 & -0.45 & 1.82 & -2.16 & 32 & -0.55 & 0.20 & -1.93 \\
\hline
\end{tabular}

For each date the log-rank abundance curve of each of the three sets of species was compared with model-derived log-normal (Normal), geometric (Geom), log-normal and log-series (Series) curves using the Akaike information criterion (AIC) test. The values in bold denote the lowest AIC value, indicating the closest fit.

core size class, with eight species in the modal size class. Considering numbers of individuals, the occasionals were distributed unevenly among the size classes, compared to the core species (Fig. 6). Thus, occupancy of size classes distinguished occasional and core species, in addition to patterns of species abundance distribution.

Overall, the abundance of a species was positively related to its presence (Fig. 3). Among the occasional species, those most often present were found in a size class occupied by a core species or in an adjacent size class. One could then further subdivide the occasional species group using abundance or presence criteria, and define a 'core occasional' group of species. For example, the set of species present on 15 or more days of the 18 dates sampled, appear to be a distinct group in terms of presence as all others were found on 13 days or fewer (Fig. 3); the set of four species thus distinguished is quite similar to the 'core species' (defined as consistently present) in terms of gape size. These relatively abundant occasional species, each of a distinct gape size, may be thought of as 'understudies' of core species. The occasional species may be able to replace the core species of the same gape size should the core species fall subject to an increase in mortality.

Although involving some perhaps arbitrary categorization, we believe that it may be useful to distinguish subgroups of potential colonizers and true ephemerals among occasional or satellite species. Furthermore, the log-series distribution characteristic of the occasional species assemblage (which produces a log-series pattern for the entire tintinnid community) could largely be the product of the truly ephemeral species. For the truly ephemeral species, food resources may simply be insufficient or of an inappropriate size. Ritchie (1997) predicted theoretically that scarce food can lead to effective dispersal limitation and this might explain why the 'occasional community' appears to be, at least in part, a random collection of species. Our analysis shows that exclusion of rare species yields a log-normal distribution of relative species abundance, as has been found in other groups. This finding suggests that log-series distributions may indeed simply reflect the result of intensive sampling effort (required to detect rare species) rather than a distinct community organization. Conversely, we cannot exclude the possibility that super-intensive sampling (e.g. examining $1000 \mathrm{~L}$ rather than $60 \mathrm{~L} \mathrm{day}^{-1}$ ) may have revealed an invariant species assemblage with a log-normal distribution.

Overall, we found, among planktonic protists, consistent characteristics of species diversity over a time period equivalent to $c .30$ generations. The community appeared to be a composite community of core and occasional species with distinct species abundance distributions, much like those found in higher organisms with high dispersal capabilities (e.g. Magurran \& Henderson, 2003; Ulrich \& Ollik, 2004; Ulrich \& Zalewski, 2006). The morphological characteristics of core and occasional assemblages differed in terms of the distribution of species and abundances among LOD size classes. Occasional species appeared to contain both truly ephemeral forms as well as relatively abundant species resembling core species in morphology. Given the commonality in patterns between microbes and other organisms that we and others have found 
(e.g. Hillebrand et al., 2001; Popatova \& Charles, 2002; Soininen \& Heino, 2005), unicellular organisms such as tintinnids may provide a means to examine the dynamics of occasional or rare species.

\section{ACKNOWLEDGEMENTS}

Sampling was conducted as part of the PECHE programme supported by the INSU-CNRS through the PROOF programme (JGOFS-France). This paper is dedicated to Valerie Andersen who organized the DYNAPROC 2 cruise and passed away in March 2007. We gratefully acknowledge the efforts of the anonymous referees and the editors whose comments led to significant improvements in this paper. This study was conducted in the framework of the Aquaparadox project, financed by the Agence National de Recherche programme 'Biodiversite' and the Pôle Mer PACA.

\section{REFERENCES}

Agatha, S. \& Strüder-Kypke, M.C. (2007) Phylogeny of the order Choreotrichida (Ciliophora, Spirotricha, Oligotrichea) as inferred from morphology, ultrastructure, ontogenesis, and SSrRNA gene sequences. European Journal of Protistology, 43, 37-63.

Broglio, E., Johansson, M. \& Jonsson, P.R. (2001) Trophic interactions between copepods and ciliates: effects of prey swimming behavior on predation risk. Marine Ecology Progress Series, 220, 179-186.

Burnham, K.P. \& Anderson, D.R. (2002) Model selection and multi-model inference: a practical information-theoretic approach. Springer, New York.

Campbell, A.S. (1942) The oceanic Tintinnoina of the plankton gathered during the last cruise of the Carnegie. Carnegie Institution of Washington Publication 537. Carnegie Institution, Washington, DC.

Cariou, J.B., Dolan, J.R. \& Dallot, S. (1999) A preliminary study of tintinnid diversity in the NW Mediterranean Sea. Journal of Plankton Research, 21, 1065-1075.

Davis, C.C. (1981) Variations of lorica shape in the genus Ptychocylis (Protozoa: Tintinnia) in relation to species identification. Journal of Plankton Research, 3, 433-443.

Dolan, J.R. (2000) Tintinnid ciliate diversity in the Mediterranean Sea: longitudinal patterns related to water column structure in late spring-early summer. Aquatic Microbial Ecology, 22, 20-30.

Dolan, J.R. (2005) Introduction to microbial biogeography. Aquatic Microbial Ecology, 41, 39-48.

Dolan, J.R. (2006) Microbial biogeography? Journal of Biogeography, 33, 199-200.

Dolan, J.R. \& Gallegos, C.L. (2001) Estuarine diversity of tintinnids (planktonic ciliates). Journal of Plankton Research, 23, 1009-1027.

Dolan, J.R., Claustre, H., Carlotti, F., Plounevez, S. \& Moutin, T. (2002) Microzooplankton diversity: relation- ships of tintinnid ciliates with resources, competitors and predators from the Atlantic Coast of Morocco to the Eastern Mediterranean. Deep-Sea Research Part I, 49, 1217-1232.

Dolan, J.R., Jacquet, S. \& Torréton, J.-P. (2006) Comparing taxonomic and morphological biodiversity of tintinnids (planktonic ciliates) of New Caledonia. Limnology and Oceanography, 51, 950-958.

Dolan, J.R., Ritchie, M.R. \& Ras, J. (2007) The 'neutral' community structure of planktonic herbivores, tintinnid ciliates of the microzooplankton, across the SE Tropical Pacific Ocean. Biogeosciences, 4, 297-310.

Gaston, K.J. \& Spicer, J.I. (2003) Biodiversity: an introduction, 2nd edn. Blackwell Publishing, Oxford.

Gold, K. \& Morales, E.A. (1976) Studies on the sizes, shapes, and the development of the lorica of agglutinated Tintinnida. Biological Bulletin, 150, 377-392.

Gotelli, N.J. \& Colwell, R.K. (2001) Quantifying biodiversity: procedures and pitfalls in the measurement and comparison of species richness. Ecology Letters, 4, 379-391.

Heinbokel, J.F. (1978) Studies on the functional role of tintinnids in the southern California Bight. II. Grazing rates of field populations. Marine Biology, 47, 191197.

Hillebrand, H., Waterman, F., Karez, R. \& Berninger, U.G. (2001) Differences in species richness patterns between unicellular and multicellular organisms. Oecologica, 126, 114-124.

Hubbell, S.R. (2001) The unified neutral theory of biodiversity and biogeography. Princeton University Press, Princeton, NJ.

Hutchinson, G.E. (1961) The paradox of the plankton. The American Naturalist, 95, 137-145.

Jörgensen, E. (1924) Mediterranean Tintinnidae. Report of the Danish Oceanographical Expeditions 1908-1910 to the Mediterranean and Adjacent Seas, Vol. II, Biology, No. 8, J.3 (Thor expedition). Andr. Fred. Høst and Son, Copenhagen.

Karayanni, H., Christaki, U., Van Wambeke, F., Denis, M. \& Moutin, T. (2005) Influence of ciliated protozoa and heterotrophic nanoflagellates on the fate of primary production in the northeast Atlantic Ocean. Journal of Geophysical Research - Oceans, 110, (C7) no. C07S1.

Kofoid, C.A. \& Campbell, A.S. (1929) A conspectus of the marine and fresh-water ciliata belonging to the suborder Tintinnoinea, with descriptions of new species principally from the Agassiz expedition to the eastern tropical Pacific 1904-1905. University of California Publications in Zoology, 34, 1-403.

Kofoid, C.A. \& Campbell, A.S. (1939) The Tintinnoinea of the eastern tropical Pacific. Bulletin of the Museum of Comparative Zoology of Harvard College, 84, 1-473.

Laval-Peuto, M. (1983) Sexual reproduction in Favella ehrenbergii (Ciliophora, Tintinnia): taxonomic implications. Protistologica, 19, 503-512.

Magurran, A.E. (2004) Measuring biological diversity. Blackwell Publishing, Oxford. 
Magurran, A.E. \& Henderson, P.A. (2003) Explaining the excess of rare species in natural species abundance distributions. Nature, 422, 714-716.

Marshall, S.M. (1969) Protozoa, order Tintinnia. Fiches d'indentification de Zooplancton, pp. 117-127. Conseil International pour l'Exploration de la Mer, Copenhagen.

May, R.M. (1975) Patterns of species abundance and diversity. Ecology and evolution of communities (ed. by M.L. Cody and J.M. Diamond), pp. 81-120. Harvard University Press, Cambridge.

McGill, B.J. (2003) Does mother nature really prefer rare species or are log-left skewed SADs a sampling artefact? Ecology Letters, 6, 766-773.

Pierce, R.W. \& Turner, J.T. (1993) Global biogeography of marine tintinnids. Marine Ecology Progress Series, 94, 1126.

Popatova, M.G. \& Charles, D.F. (2002) Benthic diatoms in USA rivers: distributions along spatial and environmental gradients. Journal of Biogeography, 29, 167-187.

Ritchie, M.E. (1997) Population dynamics in a landscape context: sources, sinks, and metapopulations. Wildlife and landscape ecology (ed. by J.A. Bissonette), pp. 160-184. Springer, New York.

Soininen, J. \& Heino, J. (2005) Relationships between local population persistence, local abundance and regional occupancy of species: distribution patterns of diatoms in boreal streams. Journal of Biogeography, 32, 1971-1978.

Ulrich, W. \& Ollik, M. (2004) Frequent and occasional species and the shape of relative abundance distributions. Diversity and Distributions, 10, 263-269.
Ulrich, W. \& Zalewski, M. (2006) Abundance and co-occurrence patterns of core and satellite species of ground beetles on small lake islands. Oikos, 114, 338-348.

Wasik, A. (1988) Antarctic tintinnids: their ecology, morphology, ultrastructure and polymorphism. Acta Protozoologica, 37, 5-15.

Whittaker, R.H. (1972) Evolution and measurement of species diversity. Taxon, 21, 213-251.

Williams, R., McCall, H., Pierce, R.W. \& Turner, J.T. (1994) Speciation of the tintinnid genus Cymatocylis by morphometric analysis of the loricae. Marine Ecology Progress Series, 107, 263-272.

\section{BIOSKETCHES}

John Dolan, Alina Tunin-Ley and Marie-Dominique Pizay work on planktonic protist diversity in the Microbial Ecology group in the Laboratoire d'Océanography de Villefranche at the Station Zoologique in Villefranche-sur-Mer, France.

Mark Ritchie is an ecologist at Syracuse University, New York. His research interests range from grazer-plant interactions to self-organization and fractal geometry in biological systems.

Editor: John Lambshead 